\title{
AMMONIA EMISSION EVALUATION FROM MANURE MANAGEMENT
}

\author{
Olga Frolova, Juris Priekulis, Laima Berzina, Aivars Aboltins \\ Latvia University of Agriculture \\ olga.frolova@1lu.lv
}

\begin{abstract}
Ammonia emissions are produced in all manure management cycle stages: in the livestock housing period as well as during grazing, while manure is stored and incorporated to the soil. For ammonia emission estimation from manure management in Latvia the methodology described in the EMEP-EEA guidebook 2016 is used. The research paper covers all common livestock groups as well as the major manure handling and storage technology solutions in Latvia. The ammonia emissions are overviewed according to the level of calculations (Tier 1 or Tier 2), as well as typical characteristics of small or intensive management farms. The outcome of ammonia emissions increased by $50 \%$, if Tier 2 method was used for determination of dairy cattle ammonia emissions compared to Tier 1, for laying hens this difference is $32 \%$. Conventional farming contributes less ammonia emissions for dairy cattle (52\%) and laying hens (44\%) compared to intensive farming in the context of Tier 2 calculation approach, if abating solution quantitative expressions are not taken into account. Substantial reduction potential (up to $64 \%$ for dairy cattle) can be reached for ammonia emission, if manure is used as feedstock for biogas production as direct use of manure is subtracted from Tier 2 calculations and for this research comparison purposes calculated using Tier 1 level methodology. The emission created from biogas production is necessary to report in the waste sector according to the UNECE Convention on Long-range Transboundary Air Pollution (CLRTAP)p directive. Quantitative estimation of abating and preventing solutions for ammonia emissions at all levels of manure management according to the country specific conditions is important.
\end{abstract}

Keywords: air pollutants, agriculture, dairy cattle, fattening pigs, laying hens.

\section{Introduction}

The main source of ammonia emission is agriculture. According to the Latvian inventory 2017 for the 2015 accounting year, agricultural production caused $16 \mathrm{kt}$ or $86 \%$ of total ammonia emission [1]. Ammonia emission is produced in all manure management cycles. In Europe during period 1990-2014 have dropped because of reduced livestock numbers and nitrogenous fertilizer use, but now there is tendency in some countries that emissions increase. Agricultural sector contributes $94 \%$ of ammonia emission in Europe [2]. In 2015, $46 \%$ of the Latvian agricultural ammonia emission is from manure management (emissions from animal housing, pasture and manure storage), but $54 \%$ from agricultural soils, where emissions from manure and digestate as organic fertilizer incorporation are also included [1].

Latvia as the other European Union countries must take annual ammonia emission inventory according to several directives. On 14 December 2016, the European Parliament and Council Directive (EU) 2016/2284 on reduction of national emissions of certain air pollutants into the air was adopted and the Directive 2003/35 / EC was amended and the Directive 2001/81 / EC (hereinafter Directive 2016 / 2284) was annulated [3]. According to the Directive 2016/2284 it is fixed that Latvia has to submit a report on air pollutants each year from different sectors, including the agricultural sector, in order to verify whether Latvia meets its set targets. The report results can be used in the relevant sectoral policy planning. In preparation of the report a specific methodology is used. The technical guidance to prepare national emission inventories is available at the joint EMEP/EEA air pollutant emission inventory guidebook, which supports the reporting of the emission data under the UNECE Convention on Long-range Transboundary Air Pollution (CLRTAP) and the EU National Emission Ceilings Directive. The Guidebook is published by the European Environment Agency (EEA) [4].

Emission calculations can be done in several levels. The simplest is the Tier 1 level when emissions are calculated according to the country current number of livestock and in the manual given default factors. The Tier 2 level, where in the calculation of emissions manure management solutions are enclosed, is more accurate. Another possibility is to use the Tier 3 level, based on national studies and the developed ammonia emission calculation models. EMEP-EEA-Guidebook 2016 states that in the EU Member States, which do not have Tier 3 national calculation models for ammonia emissions, inventory should be made by the manual first or second level methods and this indication applies also to Latvia [4]. 
At present, our country is using in the guidelines described emission calculation methodology. However, emission values need to be assessed detailed depending on the species of farm animals and the possible manure management options. The aim of research is to determine the difference of calculated emissions by livestock handling alternatives using methodology of EMEP/EEA air pollutant emission inventory guidebook, as well as to highlight abating strategies according to estimation approach. Therefore, this article summarizes ammonia emission calculation results obtained by the Tier 1 and Tier 2 level methodologies covering Latvian common livestock groups and major manure management technology solutions.

\section{Materials and methods}

Our previous studies $[5 ; 6]$ show that the manure type and management solution is highly dependent on the shed based herd size. For instance, in the large livestock farms where 200 and more cows are sited, animals are kept untied and on a slurry based manure management system. In contrast, in small establishments, which do not have more than 50 dairy cows, they are tied and livestock manure is obtained as solid. Moreover, a similar situation can be observed dealing with other livestock. Therefore, in the research three major livestock groups are selected: dairy cows, fattening pigs and laying hens. For each of these groups ammonia emission has been calculated based on three scenarios for manure management.

Alternative 1. The animals are kept in small farms. Therefore, cows are hold tied, but in summer they are grazed. Pigs are kept in pens with straw bedding, but laying hens - on deep litter with options to walk outside. In all these cases, the animal produces solid livestock manure, which is accumulated in a storage facility and used as fertilizer on the fields.

Alternative 2. The animals are kept in large farms. Dairy cows are hold inside stables loose and grazing is not acquired, pig pens are located on slatted floors, and laying hens are caged in batteries. In this case, slurry from cattle, pig and laying hen holdings is obtained. The resulting manure is accumulated in specially installed storage facilities and used as fertilizer on the fields.

Alternative 3. Animals are kept in large farms, but in contrast to Alternative 2 the resulting manure is used for biogas production. The most important input data used in the calculations are summarized in Table 1.

Table 1

Research input data

\begin{tabular}{|c|c|c|c|c|}
\hline \multirow{2}{*}{ Parameters } & Alternative & \multicolumn{3}{|c|}{ Livestock category } \\
\cline { 3 - 5 } & number & Dairy cows & Fattening pigs & Laying hens \\
\hline Housing period & 1 & 200 & 365 & 125 \\
\cline { 2 - 5 } Usage of straw, kg per day & 2 & 365 & 365 & 365 \\
\cline { 2 - 5 } & 1 & 2.3 & 0.25 & $\begin{array}{c}\text { kg per } \\
1000 \text { hens }\end{array}$ \\
\cline { 2 - 5 } Manure storage solution & 2 & - & - & - \\
\cline { 2 - 5 } & 2 & $\begin{array}{c}\text { Slurry storage } \\
\text { house with } \\
\text { floating cover } \\
\text { - natural crust }\end{array}$ & $\begin{array}{c}\text { Slurry storage } \\
\text { house with } \\
\text { floating cover } \\
\text { - plastic } \\
\text { sheeting }\end{array}$ & $\begin{array}{c}\text { Storage in } \\
\text { pile without } \\
\text { litter }\end{array}$ \\
\hline
\end{tabular}

Ammonia emission calculations from manure management were made by using the Tier 1 and Tier 2 level methodologies. It is assumed that in all housings the number of livestock is 100. In the study the default $\mathrm{N}_{\mathrm{ex}}-\mathrm{N}$ excreted and deposited in the livestock house is used. Manure storage default facto for laying hens is used to determine emission during pastures as required is not specified in the guidelines [4]. The Tier 1 of the EMEP-EEA guidelines, which is the only currently available methodology, is used to calculate the emissions during incorporation of digestate to the soil. Emission arising from the biogas production process is necessary to report in the waste sector, but to show the impact of biogas emissions, the calculation was carried out using the Tier 1 level. 


\section{Results and discussion}

Each of the previously described techniques including different amounts of raw data are shown in (Table 2).

Input data for Tier 1 and Tier 2 level calculations

Table 2

\begin{tabular}{|c|c|c|c|}
\hline \multicolumn{2}{|c|}{ Tier 1 } & \multicolumn{2}{c|}{ Tier 2 } \\
\hline Number & Input parameter & Number & Input parameter \\
\hline 1 & Animal species, age group & 1 & Animal species, age group \\
\hline 2 & $\begin{array}{c}\text { Number of animals by } \\
\text { certain groups }\end{array}$ & 2 & $\begin{array}{c}\text { Number of animals by } \\
\text { certain groups }\end{array}$ \\
\hline 3 & The resulting manure type & 3 & The resulting manure type \\
\hline 4 & $\begin{array}{c}\text { Ammonia emission } \\
\text { factors }\end{array}$ & 4 & $\begin{array}{c}\text { Ammonia emission } \\
\text { factors }\end{array}$ \\
\hline- & - & 5 & Housing period \\
\hline- & - & 6 & Amount of used straw \\
\hline- & - & 7 & $\begin{array}{c}\text { Type of manure } \\
\text { management system }\end{array}$ \\
\hline- & - & 8 & $\begin{array}{c}\text { Direct manure application } \\
\text { feedstock for biogas or } \\
\text { application to soil) }\end{array}$ \\
\hline
\end{tabular}

The Tier 1 level methodology includes general information from which you can calculate the resulting amount of manure, but the Tier 2 methodology also takes into account data of livestock keeping characteristics and manure storage types. The reference emission level is calculated. Technology improvement, which causes reduction of emission, is evaluated during interpretation of the results, reducing them by the part associated to the abating technique described in the Economic Commission for Europe Guidance document, which is the executive body for the Convention of Long - range Transboundary Air Pollution [7].

The estimated ammonia emissions for one year period from dairy cow manure management are shown in Figure 1.

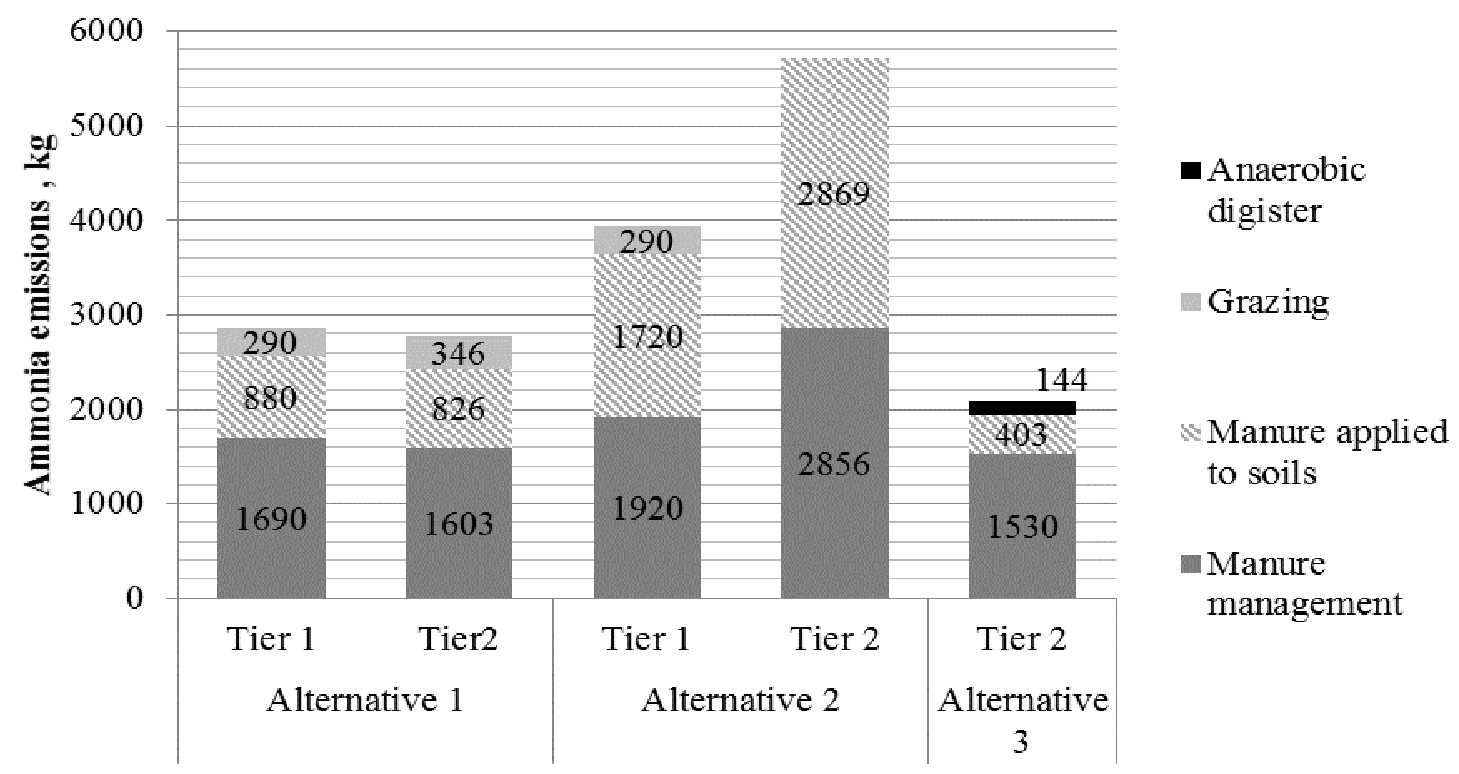

Fig. 1. Ammonia emissions from dairy cattle

As it can be seen from Figure 1, for Alternative 1 manure management option both ammonia calculation methodologies give about the same results. However, differences arise in the second alternative manure management option. In this case, approximately 2 times greater ammonia emission 
from housing, manure storage and incorporation is acquired than using the Tier 1 methodology, and about 2 times the total estimated emission of ammonia is greater (52\%). This is explained by the fact that in Alternative 2 cows are held housed throughout the year, while the Tier 1 level default emission factor is developed based on standardized livestock holding parameters, where it is assumed that dairy cows are maintained housed just for 180 days. Therefore, on the basis of ammonia emission reduction point of view, it is favorable to use cow slurry for biogas production (reduction potential $64 \%$ ) because of the relatively small emission volume, determined by the Tier 1 level and currently required to report to the waste sector. Biogas production on ammonia emissions should be evaluated in detail. Therefore, there is a need for future research.

The estimated ammonia emissions caused by growing fattening pigs are shown in Figure 2.

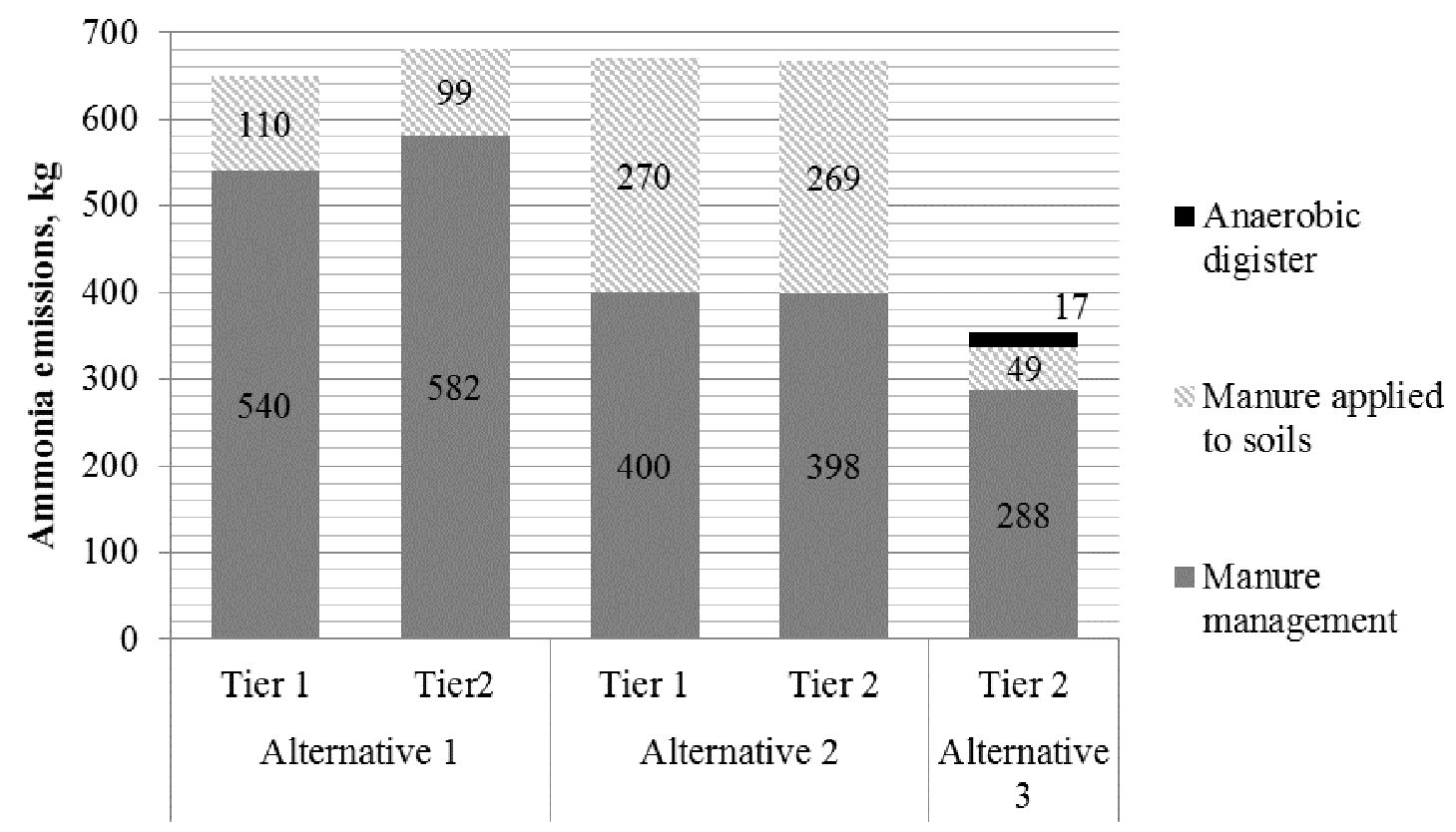

Fig. 2. Ammonia emissions from fattening swine

The results of calculations show that the transition from the Tier 1 emission calculation methodology to the Tier 2 emission calculation methodology for swine livestock category caused a larger outcome for the first alternative, where pigs are kept in small farms. However, this increase in emissions is not great (less than $5 \%$ ), and in addition, according to our researches $[4 ; 5]$ in the following establishments only about $15 \%$ of all pigs in Latvia are currently located, but $85 \%$ of pigs are kept in modern accommodations on slatted floors obtaining slurry. In the future, the increase of small pig farms is not expected, because of pig concentration in large scale farms. Therefore, in these circumstances, such ammonia emission growth using the Tier 2 calculation methodology is not relevant. There are no evident differences between the first and second alternative calculated by the Tier 2 level methodology, but it is significant that according to Alternative 3 it is desirable to use pig slurry for biogas production, because it reduces the calculated ammonia emissions around two times.

The information about the amount of ammonia emissions arising from laying hens during one year period is summarized in Figure 3. In small laying hen settlements they are kept on a litter based manure management system and during favorable weather conditions they are free to use the walking area. Therefore, using the Tier 2 calculation methodology where these factors are taken into account, the calculated ammonia emissions are $32 \%$ lower than those calculated on the basis of the Tier 1 methodology, because in the default emission factor it is assumed that they are only kept housed.

However, if the laying hens are caged in batteries, the higher emission for about $44 \%$ is calculated by the Tier 2 approach, and this increase occurs mainly because of estimation of emissions from manure incorporation into the soil. In the previous overview of livestock categories a significant reduction potential (32\%) is obtained, if poultry manure is used as feedstock in biogas facility. According to our calculations [5; 8] in Latvia currently for this purpose about $36 \%$ of the total amount of poultry manure is used. Therefore, relatively large part of manure is remaining. 


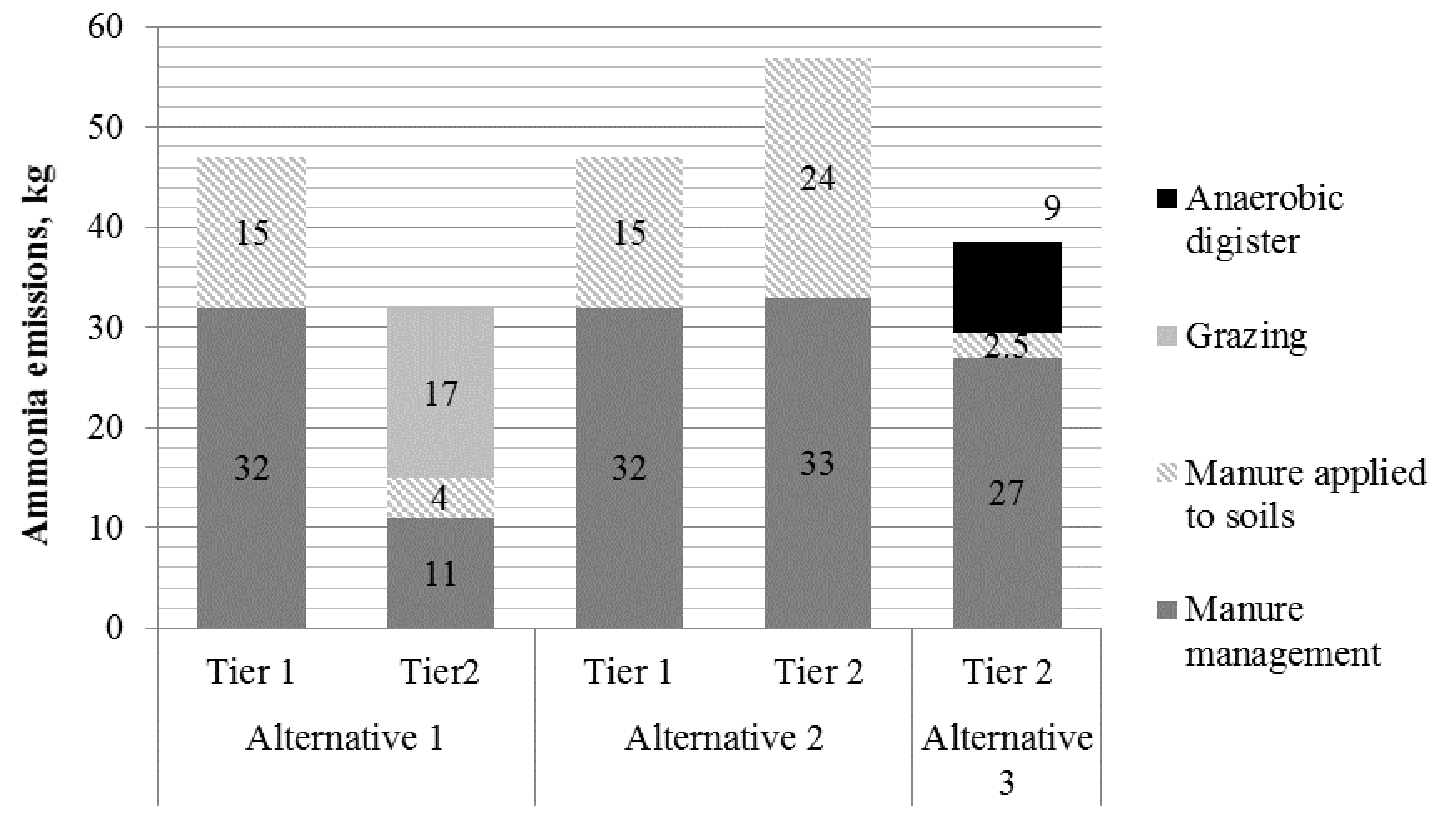

Fig. 3. Ammonia emissions from laying hens

The results of the calculations show in Figure 4 that in both alternatives the most of ammonia emissions arise during the application of livestock manure to the soil. Emissions from manure incorporation to soil form $30 \%$ of the total amount in small farms, where cows are housed tied, during good weather conditions grazed and solid manure is obtained (Alternative 1), while in large farms, where the cows are kept loose and slurry is obtained (Alternative 2), these emissions form $50 \%$. Meanwhile, in the animal housing and during manure storage calculated ammonia emissions are similar (23-29\% level). The calculated emissions during the housed period and storage can be reduced after improvements in the technology are evaluated and considered. For instance, the largest emission reductions - 70 to $90 \%$ (depending on the efficiency) [7] can be achieved if the forced ventilation system with chemical air scrubbers is installed in the housing facility.
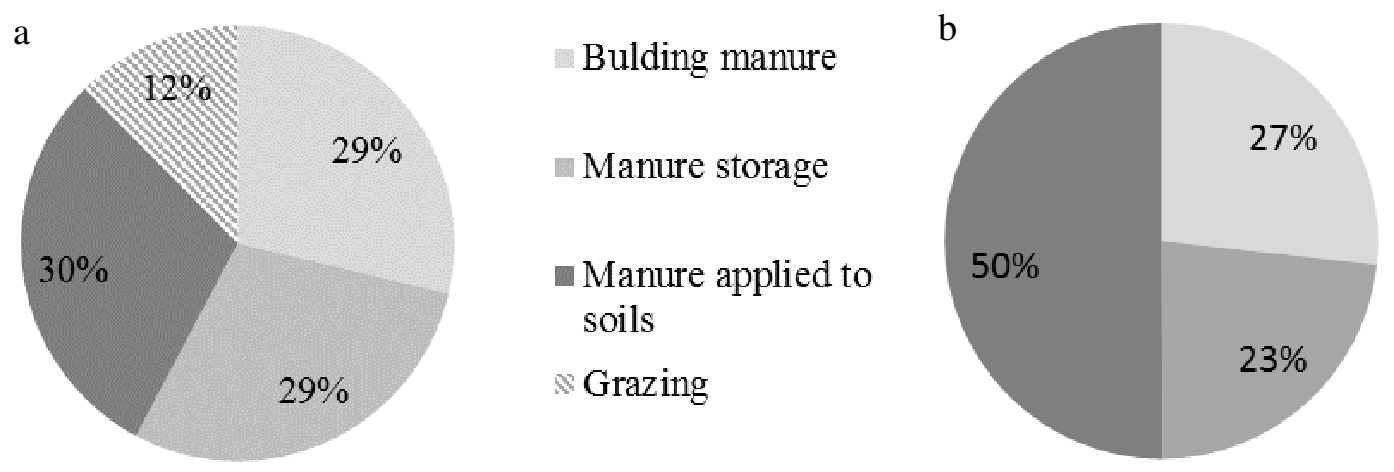

Fig. 4. Ammonia emission distribution from the different dairy cattle manure management stages calculated with Tier 2 method: a - Alternative 1; b - Alternative 2

Dairy cattle deposits manure and dung during the grazing period, which emits ammonia (Alternative 1), but this part of emissions is insignificant as it does not exceed the $12 \%$ level. Large emission reductions from manure incorporation can be obtained using a variety of incorporation techniques. The Republic of Latvia Cabinet Regulation No. 834 Adopted in 23 December 2014 Regarding Protection of Water and Soil from Pollution with Nitrates Caused by Agricultural Activity determines that the liquid manure incorporation has to be done during 12 hours after spreading [9], it already determines $30 \%$ of emission reduction, but if the incorporation period could be decreased to 4 hour time period $45 \%$ of reduction potential could be reached [7]. 


\section{Conclusions}

1. Tier 1 and Tier 2 level methodologies for ammonia emission calculations from manure management can be used. The results are not always identical. For instance, the use of the Tier 2 method for determination of dairy cattle ammonia emissions increased the outcome by $50 \%$ compared to the Tier 1, while this difference for laying hens is $32 \%$.

2. The ammonia emission increases if transition from conventional (Alternative 1) to intensive farming (Alternative 2) is made. The increase of emissions for dairy cattle is $52 \%$, bur for laying hens $-44 \%$, if calculations are done by the Tier 2 approach.

3. Substantial reduction of ammonia emission can be obtained, if manure is used as feedstock for biogas production. The emission created from biogas production, is necessary to report according the UNECE Convention on Long-range Transboundary Air Pollution (CLRTAP) directive in the waste sector.

4. In the EMEP-EEA Guidelines the Tier 2 level methodology to derive ammonia emission from digestate as organic fertilizer is not included. Therefore, it is necessary to carry out detailed research in emitted ammonia during incorporation of digestate according to the climatic and soil parameters.

5. It can be concluded that it is important to estimate ammonia emission abating and preventing solutions at all levels of manure management, as well as the quantitative reduction efficiency according to the country specifics.

\section{References}

1. Latvia Informative Inventory Report 1990 - 2015 Submitted under the Convention on Long Range Transboundary Air Pollution. [online] [16.03.2017]. Available at: http://cdr.eionet.europa.eu/lv/un/clrtap/iir/envwmlmda/

2. European Union emission inventory report 1990-2014 under the UNECE Convention on Long range Transboundary Air Pollution (LRTAP) [online] [28.04.2017]. Available at: http: //www.eea.europa.eu/publications/lrtap-emission-inventory-report-2016

3. DIRECTIVE (European Union) 2016/2284 OF THE EUROPEAN PARLIAMENT AND OF THE COUNCIL of 14 December 2016 on the reduction of national emissions of certain atmospheric pollutants. [online] [11.03.2017]. Available at: http://eur-lex.europa.eu/legalcontent/EN/TXT/?uri=uriserv \%3AOJ.L_.2016.344.01.0001.01.ENG

4. EMEP/EEA air pollutant emission inventory Guidebook 2016. [online] [20.01.2017]. Available at: http://www.eea.europa.eu/publications/emep-eea-guidebook-2016

5. Laurs A., Priekulis J., Markovics Z. and Aboltins A. Research in farm animal breeding technological parameters. Proceedings of 15th International Scientific Conference "Engineering for rural development”, May 25-27, 2016, Jelgava, Latvia, pp.1054-1058.

6. Laurs A., Markovics Z., Priekulis J., Aboltins A. Research in farm management Technologies using the expert method. Agronomy Research, vol. 14, No 3, 2016, pp.811-820.

7. United Nations Economic and Social Council Economic Commission for Europe Executive Body for the Convention on Long-range Transboundary „Air Pollution Guidance document on preventing and abating ammonia emissions from agricultural sources" [online] [27.01.2017]. Available at: https://www.unece.org/fileadmin/DAM/env/documents/2012/EB/ECE_EB.AIR_

8. 120_ENG.pdf

9. Priekulis J., Laurs A., Aplocina E. Problemy intensyfikacji produkcji zwierzęcej na tle ochrony środowiska i standardow unii europejskiej (Determination of percentage of poultry manure management systems). Instytut Technologiczno-przyrodniczy w Falentach: Institute of Technology and Life Sciences. Monografia pod redakcją naukovą prof. dr hab. inž. W. Romaniuka.: monograph. Warszawa, 2015, pp.169-173.

10. Republic of Latvia Cabinet Regulation No. 834 Regulation Regarding Protection of Water and Soil from Pollution with Nitrates Caused by Agricultural Activity. 2014. 